\title{
Voter, élire pendant la Révolution française (1789-1799). Guide pour la recherche
}

\section{Philippe Bourdin}

\section{(2) OpenEdition \\ 1 Journals}

\section{Édition électronique}

URL : https://journals.openedition.org/ahrf/1143

DOI : 10.4000/ahrf.1143

ISSN : 1952-403X

Éditeur :

Armand Colin, Société des études robespierristes

\section{Édition imprimée}

Date de publication : 1 septembre 2001

Pagination : 132-137

ISSN : 0003-4436

\section{Référence électronique}

Philippe Bourdin, «Voter, élire pendant la Révolution française (1789-1799). Guide pour la recherche », Annales historiques de la Révolution française [En ligne], 325 I juillet-septembre 2001, mis en ligne le 10 avril 2006, consulté le 23 avril 2022. URL : http://journals.openedition.org/ahrf/1143 ; DOI : https:// doi.org/10.4000/ahrf.1143

Ce document a été généré automatiquement le 23 avril 2022.

Tous droits réservés 


\title{
Voter, élire pendant la Révolution française (1789-1799). Guide pour la recherche
}

\author{
Philippe Bourdin
}

\section{RÉFÉRENCE}

Serge Aberdam et alii, Voter, élire pendant la Révolution française (1789-1799). Guide pour la recherche, Paris, C.T.H.S., 1999, 484 p.

1 Ce guide est issu d'un atelier de recherche né en 1991 au sein de l'Institut d'Histoire de la Révolution française, dont les réunions régulières ont fait la preuve du dynamisme et fondé des échanges de qualité entre chercheurs de plusieurs horizons, s'interrogeant sur les origines et les pratiques du suffrage en France. L'initiative, soutenue à son origine par Michel Vovelle et principalement conduite par Serge Aberdam et Bernard Gainot, a été ainsi enrichie par beaucoup de leurs «égaux en droits» qu'ils ont su y associer, venus les rejoindre depuis la France ou l'étranger.

B.Gainot rappelle la genèse des études électorales sur la Révolution, dont la richesse et les limites motivaient le débat et le renouvellement des chantiers. Lequel d'entre nous n'a pas eu recours aux grandes synthèses départementales plus attentives à l'histoire sociale qu'à la description du moment électoral (P. Bois, M. Reinhard, P.Clémendot, R. Marx, J. Brelot, H. Pommeret), n'a pas ipso facto été séduit par la nouveauté des analyses $\mathrm{du}$ vote en assemblée produites par J.-R. Suratteau, par cet apprentissage de la démocratie auquel se sont attachés A. Soboul et M. Genty Les écrits de P. Rosanvallon et de M. Gauchet sur la citoyenneté, ceux de P. Guéniffey et de M. Crook sur les pratiques, les tâtonnements des premiers suffrages, confrontés à une culture politique dominante peu favorable au pluralisme des candidats et des programmes, remarquent aussi l'adoption progressive par la classe politique du principe de légitimation par l'élection. L'utilisation de la prosopographie paraît alors incontournable pour mieux connaître un 
corps électoral qui figurait un intermédiaire entre les citoyens et les représentants E.Ducoudray en a fait la démonstration pour Paris. En même temps apparaissent les impératifs et les limites de l'enquête la nécessaire interrogation sur les racines des comportements électoraux (donc sur les traditions communautaires, que soulignent notamment les travaux de S.Bianchi, M. Edelstein, G.Fournier, J.-P. Jessenne et C. Wolikow), la difficile interprétation des cartes départementales à travers les seules attitudes des élus dans les assemblées révolutionnaires. S.Aberdam démontre les rythmes contrastés de l'élargissement du suffrage universel masculin au début de la première République. Aborder le suffrage revient aussi à mesurer l'appréhension du nouvel espace administratif par les Français, une mesure à laquelle inclinent les choix privilégiés de certains scrutins (celui du juge de paix dans les circonscriptions rurales), les degrés de politisation observés (plus importants lors des assemblées électorales), la persistance d'assemblées communautaires. S'impose enfin l'essai d'interprétation d'une chronologie de la mobilisation, marquée de manière non uniforme par une désaffection paysanne sous le Directoire, à partir de l'an VII notamment - refus d'une nationalisation des enjeux politiques imposée une fois l'an par les échéances nationales (P. Jones, I. Woloch), dislocation des vieilles communautés sous l'effet des mesures révolutionnaires (J.-P. Jessenne, F. Fortunet, S. Aberdam), résistances aux agressions de l'État en matière religieuse ou militaire (R. Dupuy) sont les causes les plus souvent évoquées.

B.Gainot esquisse également un historique des procédures de désignation. Il rappelle opportunément que "le fait de pourvoir un poste, une place, une charge, par l'élection, n'apparaît pas en 1789, avec la campagne pour les États généraux que l'élection n'est d'ailleurs pas, dans la tradition républicaine, l'unique procédé de nomination (le tirage au sort des républiques antiques ne sera pas oublié par les révolutionnaires) que la tradition républicaine n'est pas la seule à légitimer l'élection, utilisée par plusieurs institutions religieuses, à commencer par les chapitres, ou, dans la société laïque, par les assemblées de ville, les jurandes, les communautés rurales, qui contribuent à fixer diverses techniques de scrutin. Alors, "chaque élu est lié à ses électeurs et commettants par un mandat impératif, auquel Turgot et Dupont de Nemours en 1775 vont tenter sans succès de substituer pour partie un mandat représentatif le Mémoire sur les municipalités du second sera pourtant repris et modifié à partir de 1787 par Calonne puis par Loménie de Brienne. Ce dernier tente dans les pays d'élection l'instauration, selon un modèle en partie censitaire, de plusieurs degrés d'assemblées élisantes, nettement séparées des assemblées délibérantes.

Mais il faut attendre les efforts du parti patriote en 1789 pour qu'émerge un véritable système représentatif si l'on excepte le pouvoir exécutif et ce qui en relève, l'élection devient "l'unique instance de légitimation, à tous les niveaux et pour pratiquement toutes les fonctions officielles. Sa fréquence est remarquable "deux à trois consultations dans l'année sous la monarchie constitutionnelle deux référendums sur les actes constitutionnels en trois ans sous la Convention une consultation annuelle sous le Directoire, mais avec des opérations regroupées sur tout un mois. La vénalité abolie, fonctions judiciaires, administratives, religieuses, militaires sont conférées par le suffrage, selon des modalités variables d'une constitution à l'autre, que nous rappelle B.Gainot avant de décrire les modalités des votes pour les assemblées primaires et électorales - inscription dans le calendrier annuel le second ou le dernier dimanche de mars, puis le 1er et le 20 germinal à partir de l'an $\mathrm{V}$ configuration des circonscriptions, avec un poids éminent des sections urbaines jusqu'en l'anIII au moins; choix du 
lieu pour un instant sacralisé en temple de la souveraineté populaire déroulement très ordonné et ritualisé de la journée de scrutin (nomination du bureau, analyse du registre civique ou vérification des pouvoirs des électeurs selon l'échelon de désignation, serment constitutionnel, lecture des procès-verbaux des séances antérieures au-delà d'une demi-journée de réunion) originalité des procédures référendaires de 1793 et de l'anIII, libérées de la contrainte censitaire, associant délibération et élection pour approuver et amender les textes constitutionnels (en 1795 cependant, nuances notables, les militaires votent en corps et aucun mandataire ne porte à Paris les vœux des assemblées). Le tout ne va pas sans fraude et sans incidents, minoritaires cependant et dus essentiellement au bourrage des urnes, à la falsification de bulletins manuscrits, au jeu sur les homonymies, à la duplicité des scrutateurs sans pressions sur des électeurs soumis aux mots d'ordre des sociétés politiques (doublés de véritables actes de candidatures et de scissions autoritaires des assemblées, sous le Directoire notamment), à des hiérarchies professionnelles, à des rapports de clientèle, ou achetés. Le tout ne concerne enfin qu'un corps électoral réduit par des limites censitaires, patriotiques -fondées sur l'obtention ou non d'un certificat de civisme -, politiques exclusion des émigrés, des prêtres réfractaires, des déserteurs, etc. -, culturelles - rejet, à nuancer selon les votes et les lieux, d'une expression féminine, acceptée parfois pour la constitution de 1793 ou lors d'assemblées communales sur le partage des communaux.

Une fois cette complexité d'appréhension et cette diversité des phénomènes électoraux constatées, les auteurs dressent l'état des sources primaires aux Archives nationales, dans les archives départementales et communales. Ils font une place à part à Paris, aux départements réunis (Alpes-Maritimes, Belgique, Pays-Bas) et aux colonies, puis proposent une sélection des sources imprimées sur le travail législatif des révolutionnaires, l'histoire politique et le vote (distinguant études générales et monographies locales et régionales). Suit une publication sous une forme abrégée des textes officiels régissant l'activité électorale de 1789 à 1799, classés selon la chronologie des Assemblées et des régimes (de la Constituante à la Convention puis au Directoire) ceux qui se rapportent aux États généraux sont exclus, au contraire de trois décisions postérieures au 18 Brumaire, qui rendent sensible la rupture. Ces documents officiels sont mis en balance avec d'autres, recueillis lors d'enquêtes de terrain, consacrés aux pratiques et comportements politiques, qui nourrissent la quatrième partie de l'ouvrage. Parfois précédés d'une courte notice de présentation, ils privilégient les incidents et contestations lors des assemblées primaires, en 1790 et sous le Directoire particulièrement, et couvrent une zone géographique qui passe au large des départements du Centre et du Massif Central (quoique les sources ne manquent pas pour l'un et l'autre). Le Guide se referme sur un ensemble d'outils de travail, à l'exception d'une cartographie, encore prématurée une table chronologique des imprimés du recueil de textes officiels et, pour consulter plus facilement ces derniers, un répertoire méthodique par mots clés un calendrier des élections sur la décennie révolutionnaire un tableau résumant les conditions successives d'exercice de la citoyenneté politique un lexique enfin. Chacun comprendra le grand intérêt de ce travail collectif. Il faut souligner ici la valeur de l'association, qui n'est pas si effective en matière de recherche, et l'abnégation de ses membres, qui, en femmes et en hommes des Lumières, ont su se dévouer à l'utilité commune. La reconnaissance n'a pas tardé l'ouvrage est déjà devenu un usuel pour tous ceux qui travaillent sur l'histoire politique de la Révolution. 